Article

\title{
Corrosion and Thermal Fatigue Behaviors of TiC/Ni Composite Coating by Self-Propagating High-Temperature Synthesis in Molten Aluminum Alloy
}

\author{
Chenggang Pan ${ }^{1, *}$, Dudu Liu ${ }^{1}$, Chuanxiang Zhao ${ }^{1}$, Qingming Chang ${ }^{1}$ and Peng $\mathrm{He}^{2}$ \\ 1 The State Key Laboratory of Refractories and Metallurgy, Wuhan University of Science and Technology, \\ Wuhan 430081, China; 15827018554@163.com (D.L.); fly250753253@sina.cn (C.Z.); qmchang@163.com (Q.C.) \\ 2 Wuhan Second Ship Design and Research Institute, Wuhan 430205, China; whlghepeng@sina.com \\ * Correspondence: panchenggang@wust.edu.cn; Tel.: +86-27-6886-2234
}

Academic Editor: Antonella Rossi

Received: 18 September 2017; Accepted: 13 November 2017; Published: 18 November 2017

\begin{abstract}
TiC/Ni composite coatings on $\mathrm{H} 13$ steel plates were fabricated in situ by self-propagating high-temperature synthesis and combined with a pseudo-heat isostatic press. The microstructure of the coating was characterized by X-ray diffraction and scanning electron microscopy. The microhardness, corrosion, and thermal fatigue behaviors of the coating were investigated by a microhardness test, immersion test, and thermal fatigue test, respectively. The results showed that the in situ coating consisted of $\mathrm{TiC}$ and $\mathrm{Ni}$ binder phases. Spheroidal TiC particles were enveloped by a nearly continuous $\mathrm{Ni}$ binder phase. Coating showed good metallurgical bonding in the interface. The corrosive mechanism of the coating surface in molten aluminum alloy involves the Ni binder phase being etched by aluminum to form $\mathrm{AlNi}_{3}$ and the oxidization of the TiC-reinforced phase. The corrosive mechanism that occurred at the front of the corrosion involves the Ni binder phase of the coating being etched by aluminum to form $\mathrm{AlNi}_{3}$, while the $\mathrm{TiC}$ skeleton still maintains the original organizational structure. Hot fatigue cracks began at the defective tips of the coating and propagated in the TiC-reinforced phase. The crack is a trans-granular fracture, which is the result of brittle rupture.
\end{abstract}

Keywords: $\mathrm{TiC} / \mathrm{Ni}$; coating; self-propagating high-temperature synthesis; corrosion; thermal fatigue; molten aluminum alloy

\section{Introduction}

Die casting dies are exposed to high-temperature molten metals, high pressures and flow velocities, as well as large thermal gradients, which result in the initiation of a variety of mechanochemical failure mechanisms. The main failure modes of die casting dies involve heat cracking or thermal cycling inducing fatigue cracking, erosive wear by molten metal, or corrosion from cast metal during die filling or soldering [1-4]. Research has indicated that surface treatment and coating could be an effective way to protect die surfaces from thermal fatigue and extend die life by reducing the damage at contact surfaces [5]. Several surface modification methods, such as physical vapor deposition (PVD), chemical vapor deposition (CVD), ion implantation, thermal spray, self-propagating high-temperature synthesis (SHS), as well as laser and plasma cladding, have been adopted to produce coatings of carbide, nitride, boride, and silicide for enhancing the service life of dies [1,5-9]. Among these, SHS has many remarkable advantages, such as high efficiency and purity of products, low energy and cost requirements, no high-temperature furnace process, non-polluting traits, and a relatively simple process $[10,11]$. At present, SHS is usually used to produce compounds or composite materials. 
SHS coatings are mainly applied for preparing ceramic-lined composite pipes by a centrifugal thermite process and composite coatings by the casting route. Odawara et al. [12-14] prepared in situ $\mathrm{Fe}-\mathrm{Al}_{2} \mathrm{O}_{3}$ ceramic lined pipes by the centrifugal thermite process. He et al. [8] and Yang et al. [15] prepared in situ TiC-Fe composite coatings on the surface of the metal substrate by vacuum expendable pattern casting (V-EPC) and sand mold casting, respectively. In addition, the preparation methods of SHS coating that only use one processing step were frequently combined with other methods [16], such as matches [17], induction heating [18], air furnace [19], microwave [20], concentrated solar energy treatment [21], and laser cladding [22]. Yuan et al. [17] prepared in situ synthesis of $\mathrm{TiC} / \mathrm{Cu}(\mathrm{Ni})$-reinforced metal matrix composite (MMC) coating on Q234 steel plate by SHS. Riyadi et al. [18] fabricated NiAl SHS flat coatings on a carbon steel substrate using induction heating. Mohammadkhani et al. [19] synthesized $\mathrm{FeAl} \mathrm{SHS} \mathrm{flat} \mathrm{coating} \mathrm{on} \mathrm{the} \mathrm{low} \mathrm{carbon} \mathrm{steel} \mathrm{at} 950{ }^{\circ} \mathrm{C}$ in an air furnace without external pressure. Boromei et al. [20] synthesized Ni-Al-Ti coatings on Ti substrates by microwave-assisted SHS under $0.45 \mathrm{MPa}$ uniaxial pressures. Bautista et al. [21] prepared NiAl intermetallic coatings on mild steel by a solar-assisted SHS process. Chatterjee et al. [22] fabricated $\mathrm{Al}_{2} \mathrm{O}_{3}-\mathrm{TiB}_{2}$-TiN-based coatings by combining SHS and laser surface alloying. The above-mentioned one-step self-propagating synthetic planar coating methods lacked external forces, except for the centrifugal thermite process. Compared with the SHS steel pipe coating, the preparation process of the SHS plane coating has the characteristics of an unrestrained and intense reaction. Furthermore, it is difficult to exert an external force field. Therefore, the SHS plane coating is difficult to create density in. The fabrication of the self-propagating plane coating and its application in die and/or tooling has rarely been reported.

In this work, $\mathrm{TiC} / \mathrm{Ni}$ composite coating was in situ synthesized via self-propagating high-temperature synthesis combined with a pseudo-heat isostatic press (PHIP) on H13 steel plate. Both the microstructures of the coating and the bonding state at the interface were examined. The corrosive and thermal fatigue behaviors of in situ SHS coatings in molten aluminum alloy were investigated.

\section{Materials and Methods}

\subsection{Materials}

A plain hot-work tool steel $\mathrm{H} 13$ with dimensions of $30 \mathrm{~mm} \times 30 \mathrm{~mm} \times 1 \mathrm{~mm}$ was used as a substrate. The chemical composition of substrate steel $\mathrm{H} 13$ is presented in Table 1. The substrate material was subjected to a heat treatment cycle with a final hardness value of $439 \pm 50 \mathrm{HV}_{0.2}$, before being ground by water sandpaper (180 mesh). This was followed by ultrasonic cleaning in alcoholic solution before the SHS process.

Table 1. Chemical composition of substrate steel H13.

\begin{tabular}{cccccccccc}
\hline \multirow{2}{*}{ Material } & \multicolumn{10}{c}{ Element (wt \%) } \\
\cline { 2 - 10 } & $\mathbf{C}$ & Si & Mn & Cr & V & Mo & S & P & Fe \\
\hline H13 & 0.36 & 1.0 & 0.35 & 5.13 & 1.0 & 1.43 & 0.01 & 0.015 & Bal. \\
\hline
\end{tabular}

The starting powders were made from commercial powders of Ti $(99.9 \%$ purity, Shanghai Naiou Nano Technology Co., Ltd., Shanghai, China) with an average particle size of $\sim 50 \mu \mathrm{m}$; carbon black (99.9\% purity, Tianjin Tianyi Century Chemical Products Technology Development Co., Ltd., Tianjin, China) with an average particle size of $\sim 0.2 \mu \mathrm{m}$; Ni (99.9\% purity, Shanghai Naiou Nano Technology Co., Ltd.) with an average particle size of $\sim 10 \mu \mathrm{m}$; and Mo $(99.95 \%$ purity, Shanghai Naiou Nano Technology Co., Ltd.) with an average particle size of $\sim 10 \mu \mathrm{m}$.

\subsection{Coating Procedure}

The composite coating has three layers. Table 2 shows the composition and weight of each layer. $\mathrm{Ni}$ is used as a binder phase to improve the density and strength of the coating. The transition layer 
can improve the bonding strength between the substrate and coating, while Mo can improve the wettability of $\mathrm{TiC}$ by $\mathrm{Ni}$ [23]. The reactant mixture of each layer was mixed in a ball grinding mill for $8 \mathrm{~h}$ and dried in a vacuum drying oven for $24 \mathrm{~h}$ at a temperature of $90^{\circ} \mathrm{C}$, which is followed by compaction in a stainless steel die to form a compact sample. The green density of each compact was maintained at about $55 \%$ of theoretical density.

Table 2. Material design of TiC/Ni composite coating.

\begin{tabular}{ccc}
\hline Layer & Composition (wt \%) & Weight $\mathbf{( g )}$ \\
\hline Surface layer & 20Ni-64Ti-16C & 2 \\
Interlayer & 40Ni-48Ti-12C & 2 \\
Transition layer & 10Mo-Ni & 0.3 \\
\hline
\end{tabular}

A schematic illustration of the fabrication of composite coating by SHS/PHIP is shown in Figure 1. Three powder compacts were stacked on the substrate in turn. Loose powder particles of 20Ni-64Ti-16C were wrapped around the substrate and powder compacts acted as a pressure-transmitting medium. This created a pseudo-heat isostatic press state on the compacts and compensated for the heat loss of the Ti-C-Ni reaction system. The reactor was purged and filled with argon before ignition. The combustion system was preheated to a temperature of $300{ }^{\circ} \mathrm{C}$ and then ignited using a tungsten filament. After the completion of combustion $2 \mathrm{~s}$ later, the reaction system was pressed for $20 \mathrm{~s}$ at a compaction pressure of $15 \mathrm{MPa}$.

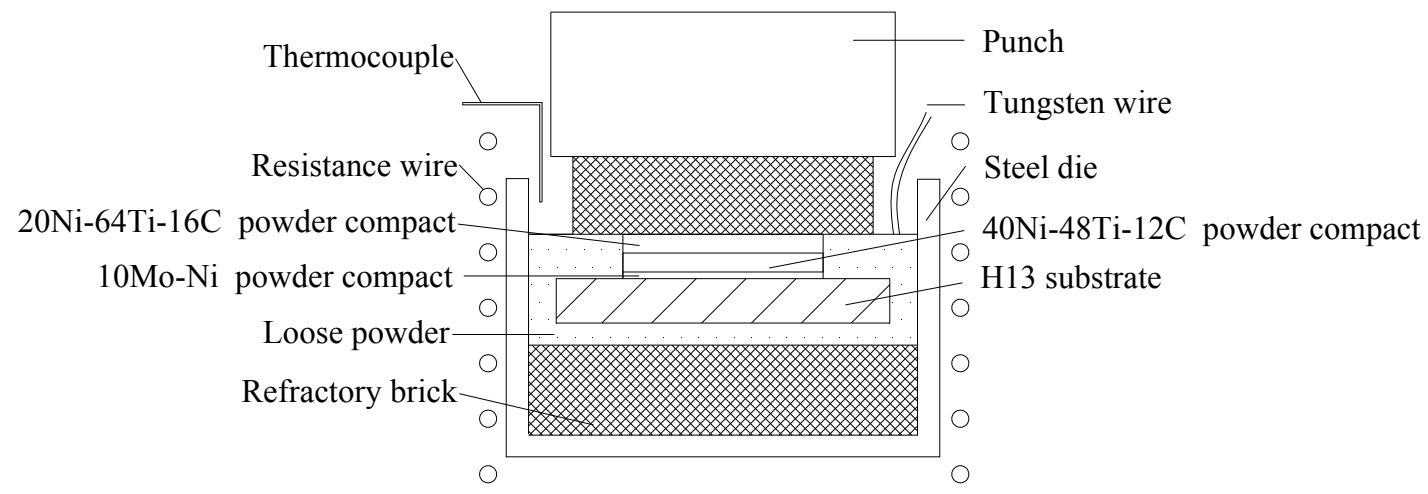

Figure 1. Schematic illustration of the fabrication of composite coating by SHS/PHIP.

\subsection{Characterizations}

The microstructural analysis of coating was conducted using a scanning electron microscope (SEM, NOVA 400 NanoSEM, FEI, Hillsboro, OR, USA) attached with an energy dispersive spectrometer (EDS). A phase analysis of coating was carried out by X-ray diffraction (XRD, X'Pert PRO MPD, PANalytical, Almelo, the Netherlands) using Cu-K $\alpha$ radiation $(\lambda=1.54056 \AA)$ in a $2 \theta$ range of $10^{\circ}-90^{\circ}$ with a scan speed of $1.2^{\circ} / \mathrm{min}$. Surface microhardness and cross-sectional microhardness of the coating were measured by the Vickers hardness tester (HV-1000A, Shen Youda Industrial (Shanghai) Co. Ltd., Shanghai, China) using an indenting loading of $50 \mathrm{~g}$ and time of $10 \mathrm{~s}$, as well as $500 \mathrm{~g}$ and $10 \mathrm{~s}$, respectively.

\subsection{Immersion Test}

The coated sample was immersed in a clay crucible filled with molten aluminum alloy (ZLD301) for $2 \mathrm{~h}$. The chemical composition of ZLD301 is provided in Table 3. The temperature of the melt was maintained at $700{ }^{\circ} \mathrm{C}$, which is slightly above the melting temperature of pure aluminum. This is generally the temperature of the melted aluminum at the time of its injection into the die cast cavity. 
After the immersion test, the coated sample was taken out and cooled in air before being divided into sections for analysis.

Table 3. Chemical composition of the ZLD301 aluminum alloy.

\begin{tabular}{cccccccc}
\hline \multirow{2}{*}{ Material } & $\mathbf{8}$ & $\mathbf{8}$ & Element (wt \%) \\
\cline { 2 - 9 } & Mg & $\mathbf{C u}$ & Si & Zn & Mn & Fe & Al \\
\hline ZLD301 & $9.8-11.0$ & 0.1 & 0.3 & 0.15 & 0.15 & 0.25 & Bal. \\
\hline
\end{tabular}

\subsection{Thermal Fatigue Test}

A schematic illustration of the thermal fatigue test apparatus is shown in Figure $2[24,25]$. It enables controlled thermal fatigue testing at conditions similar to aluminum alloy die casting. The test sample was immersed in a water-based lubricant at about $25^{\circ} \mathrm{C}$ for $7 \mathrm{~s}$, which prevented the aluminum from sticking to the test sample. After that, the sample was moved through air at $25^{\circ} \mathrm{C}$ for $15 \mathrm{~s}$ and placed into the bath of the molten aluminum alloy ZLD301 at about $700{ }^{\circ} \mathrm{C}$. After $15 \mathrm{~s}$ of immersion in this bath, the sample was air-cooled for $14 \mathrm{~s}$ before being placed into a bath of water-based lubricant. The total cycle duration is $51 \mathrm{~s}$. The test sample is not subjected to pressure or aluminum flow, unlike the die during die casting. The movements of the test sample during the test were achieved by two-screw sliding tables controlled by a two-axis numerical control system. The test sample underwent 600 cycles.

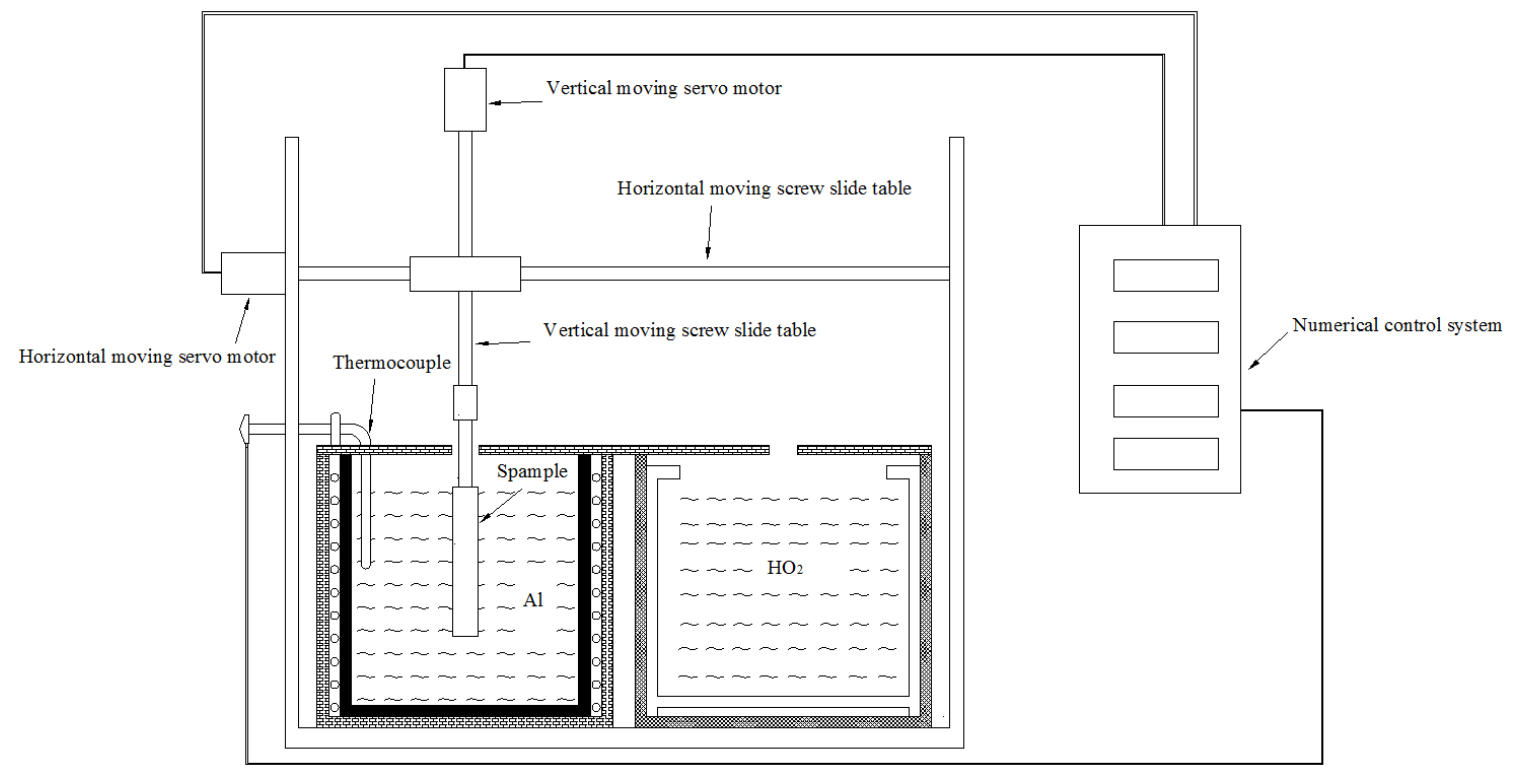

Figure 2. Schematic of thermal fatigue test apparatus.

\section{Results and Discussion}

\subsection{Phase Analysis}

The X-ray diffraction pattern of the original coating is shown in Figure 3. As shown in Figure 3, the original coating only consisted of $\mathrm{TiC}$ and $\mathrm{Ni}$ peaks. TiC and $\mathrm{Ni}$ are thermodynamically stable phases, although no Ni-Ti or Ni-Ti-C compounds were detected using X-ray diffraction analysis. Dunmead et al. [26], Zhang et al. [27], and Han et al. [28] found that the final products were TiC and unreacted $\mathrm{Ni}$ for the Ti-C-Ni system. Wong et al. [29] observed the Ni-Ti compounds ( $\mathrm{Ni}_{3} \mathrm{Ti}_{\text {or }} \mathrm{NiTi}$ ) using time-resolved X-ray diffraction on a Ti-C-25Ni reactant mixture. Xiao et al. [11] studied the mechanism of SHS of Ti-C-Ni system by means of a combustion front quenching method. They found 
that the formation of $\mathrm{Ni}_{3} \mathrm{Ti}$ phase was attributed to the incomplete reaction due to the usage of coarser $\mathrm{Ni}$ and Ti powders. In addition to the above-mentioned factors, $\mathrm{C}$ particle size [30], Ni content, and preheating temperature will also affect the degree to which the SHS reaction will be completed. Therefore, the reaction of SHS in this work was complete because of the usage of finer starting powders.

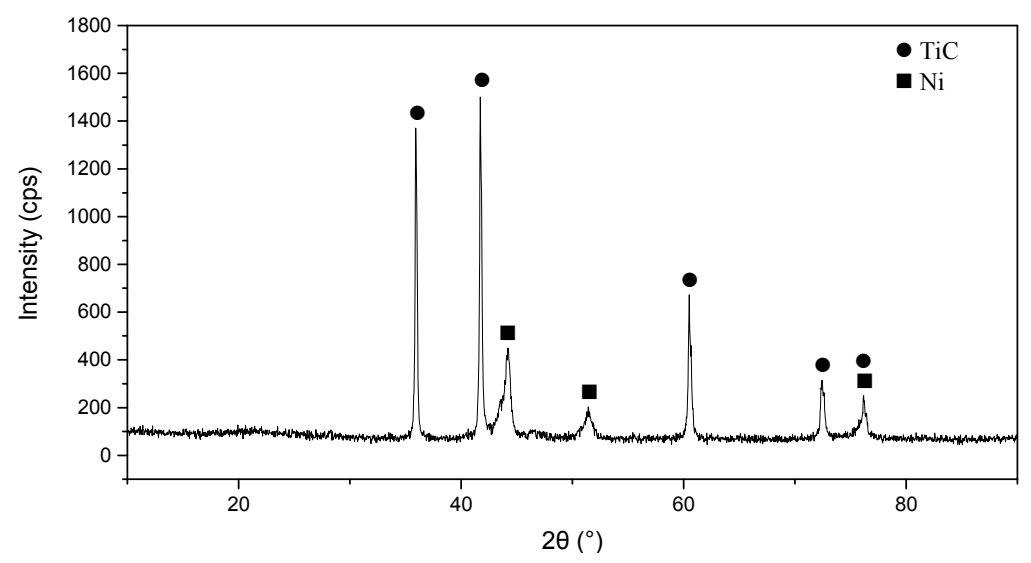

Figure 3. XRD pattern of the original coating.

\subsection{Microstructural Characterization}

Figure 4 shows the scanning electron micrographs of the surface layer and interlayer. The resulting microstructures for the $\mathrm{TiC} / \mathrm{Ni}$ coating consisted of a spheroidal TiC phase (dark) embedded in a nearly continuous Ni binder phase (white). The very fine Ni network around the TiC particles should produce a considerable increase in toughness compared with the pure TiC [31]. Moreover, as shown in Figure 4, the $\mathrm{TiC}$ size of surface layer was larger than that of interlayer. The grain growth of $\mathrm{TiC}$ is an exponential function of the combustion temperature [28]. The interlayer with $40 \mathrm{wt} \% \mathrm{Ni}$ has a low combustion temperature and long diffusion path for $\mathrm{TiC}$, which reduces the driving force for $\mathrm{TiC}$ grain growth and prevents the sintering between $\mathrm{TiC}$ grains to form larger grains.

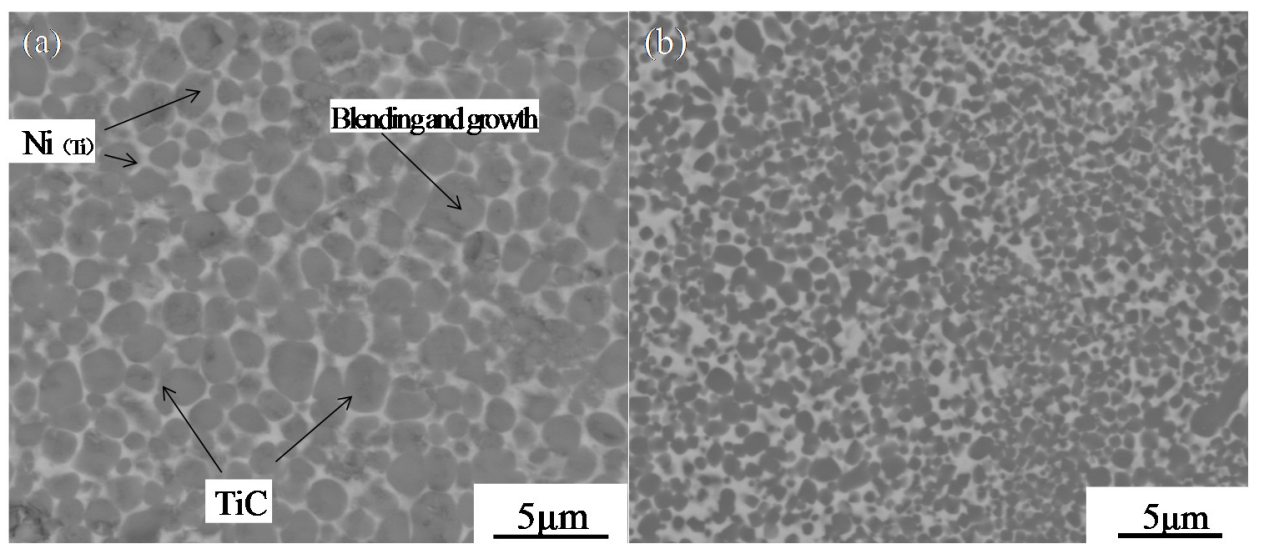

Figure 4. Microstructure of (a) surface layer and (b) interlayer.

\subsection{Bonding Performance and Microhardness}

The microstructure of the interface between interlayer and substrate is shown in Figure 5. From Figure 5, the transition layer disappeared and the interface was not flat because of high preheating temperature, which resulted in high Ti-C-Ni reaction temperature and sufficient element diffusion. Figure 6 shows the line scanning spectra of the interface between substrate and interlayer. As seen from Figure 6, the main elements for diffusion were Ti and Fe, while the diffusion distance was longer 
than $15 \mu \mathrm{m}$. The curve of Fe changed gently in the interface, while Ti showed a dramatic change. The non-flat interface and element diffusion in the interface showed good metallurgical bonding.

The surface microhardness of the original coating was $1159.06 \mathrm{HV}_{0.05}$, which was about two times the substrate microhardness of $439 \mathrm{HV}_{0.2}$. Table 4 lists the cross-sectional microhardness of the original coating. From Table 4, the cross-sectional microhardness of the original coating gradually decreased from the coating surface to the substrate. There was little difference between the surface layer and the interlayer, while the interfacial microhardness was between the substrate and the interlayer. Figure 7 shows the interfacial indentation. As shown in Figure 7, the indentation had no crack and the indentation area was very small. The above description indicated that the interface between the coating and steel substrate had strong metallurgical bonding.

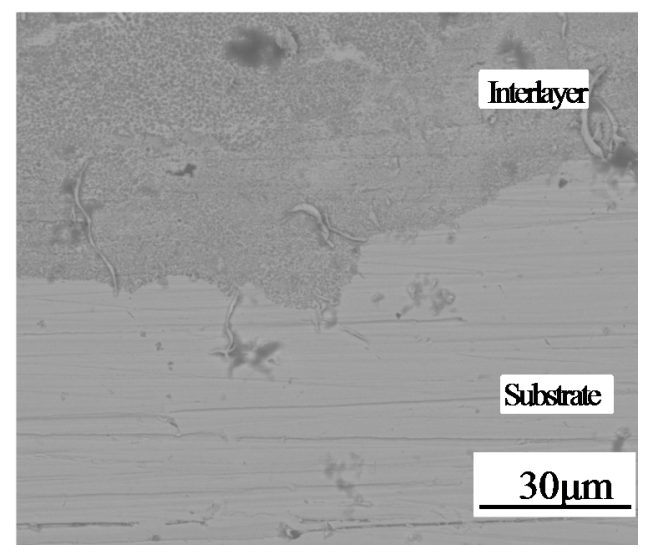

Figure 5. Microstructure of the interface between the interlayer and substrate.
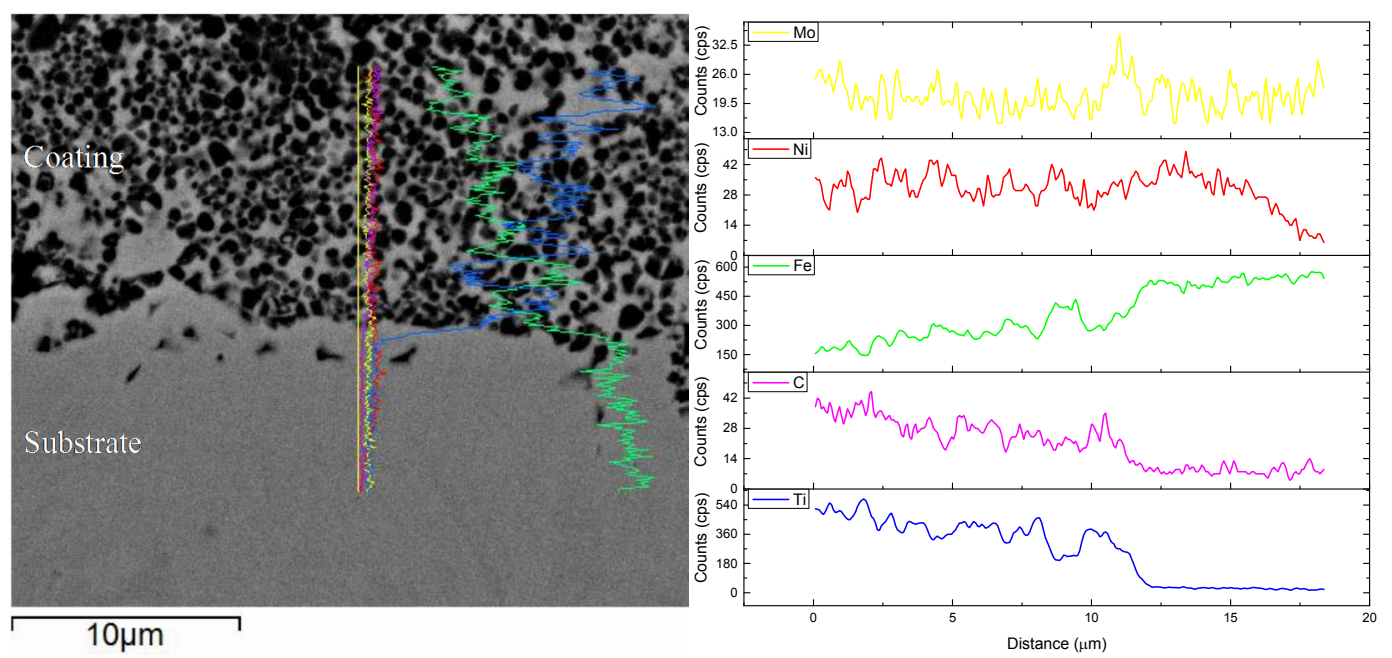

Figure 6. Line scanning spectra of the interface between the substrate and interlayer.

Table 4. Cross-sectional microhardness of the original coating.

\begin{tabular}{ccccc}
\hline Position & Surface Layer & Interlayer & Interface & Substrate \\
\hline $\mathrm{HV}_{0.5}$ & 1047.71 & 1033.30 & 784.31 & 432.54 \\
\hline
\end{tabular}




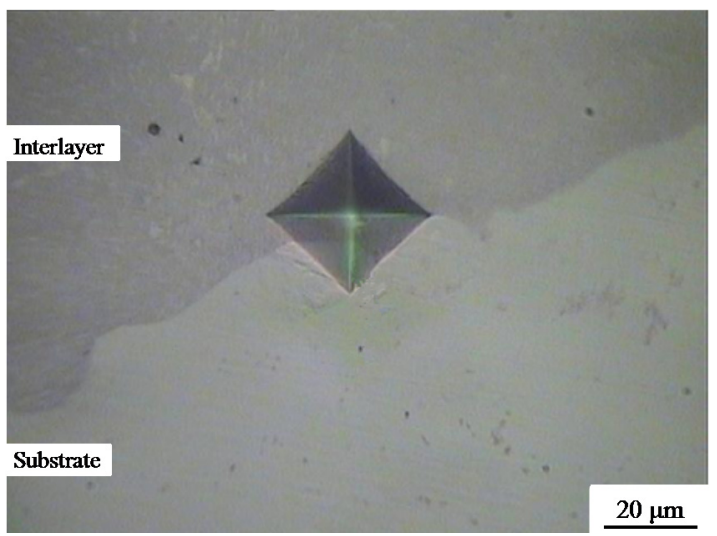

Figure 7. Interfacial indentation at a load of $500 \mathrm{~g}$.

\subsection{Immersion Test}

Figure 8 shows the XRD pattern of the original coating after immersion test. Compared with the XRD pattern of the original coating before immersion test, the new phases of $\mathrm{TiO}_{2}$ and $\mathrm{AlNi}_{3}$ appeared. As the nickel aluminum reaction is an intense exothermic reaction, Ni reacted preferentially with the $\mathrm{Al}$ of the coating surface to form $\mathrm{AlNi}_{3}$, which resulted in the $\mathrm{Ni}$ oxide peaks missing in the XRD pattern. $\mathrm{TiO}_{2}$ was caused by the oxidation of TiC.

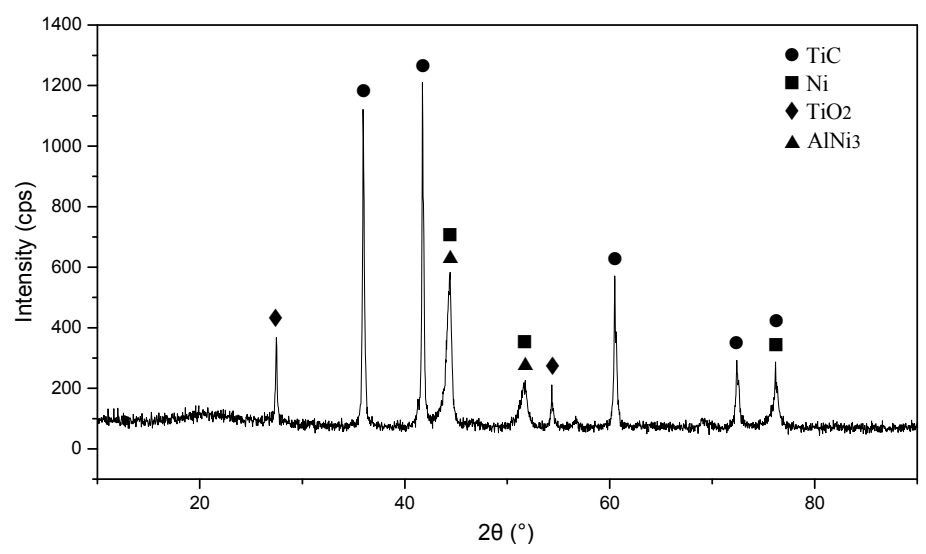

Figure 8. XRD pattern of the original coating after the immersion test.

Figure 9 shows the SEM and EDS results of the coating surface after immersion test. From Figure 9, a considerable number of white crystal particles ( 2 in Figure 9a), globular protuberances ( 3 in Figure 9a) and a few flat surfaces ( 1 in Figure 9a) appeared in the coating surface. According to the EDS results and XRD pattern (Figure 8), region 1 consisted of $\mathrm{TiC}$ and $\mathrm{TiO}_{2}$; region 2 was mainly $\mathrm{AlNi}_{3}$; and region 3 was mainly composed of $\mathrm{TiC}, \mathrm{TiO}_{2}, \mathrm{Al}$, and $\mathrm{Mg}$, which were adhered to the surface of $\mathrm{TiC}$.

Figure 10 shows the line scanning spectra from the coating surface to the inner part in the cross-section after the immersion test. From Figure 10, the local area of coating surface was exfoliated and micro-cracks were found. A large amount of $\mathrm{O}$ and $\mathrm{Al}$ appeared in the coating. The line scanning spectral fluctuation of $\mathrm{C}$ was inconsistent with $\mathrm{Ti}$ as the $\mathrm{C}$ content was less than that of Ti. Aluminum and oxygen in the molten aluminum alloy diffused inwardly by pores; $\mathrm{Al}$ reacted with the Ni binder phase to form $\mathrm{AlNi}_{3}$; and $\mathrm{O}$ reacted with $\mathrm{TiC}$ to form $\mathrm{TiO}_{2}$ and $\mathrm{C}$. Some $\mathrm{C}$ was further oxidized to produce an overflow of $\mathrm{CO}_{2}$, which resulted in a lower $\mathrm{C}$ content compared to that in Ti. Therefore, the corrosive mechanism of the coating surface in molten aluminum alloy involves the $\mathrm{Ni}$ binder phase being etched by aluminum to form $\mathrm{AlNi}_{3}$ and the oxidization of the $\mathrm{TiC}$-reinforced phase. 

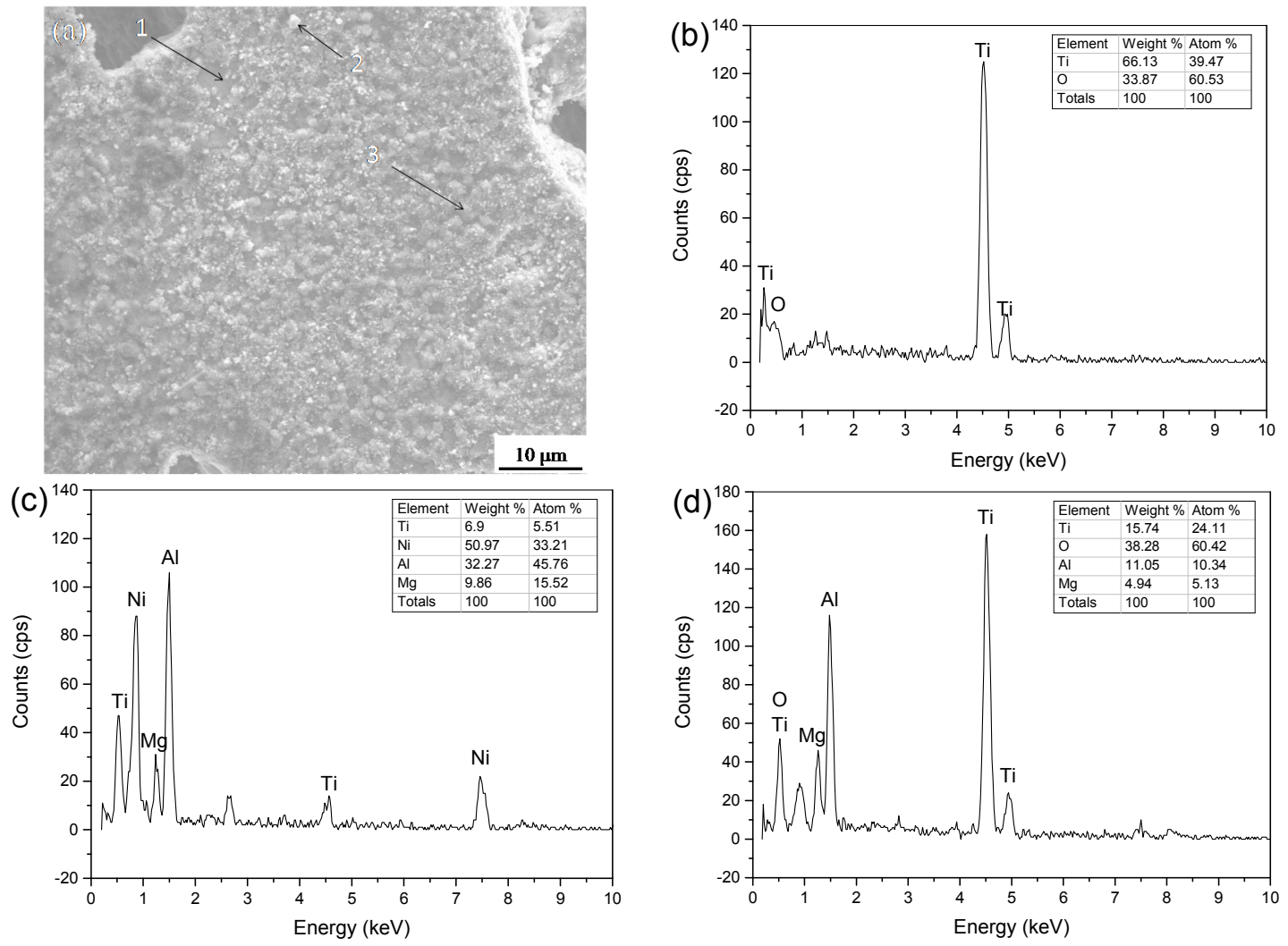

Figure 9. (a) SEM result of the coating surface after immersion test; and (b-d) EDS results of the corresponding to labeled regions, including 1, 2, and 3 in (a), respectively.
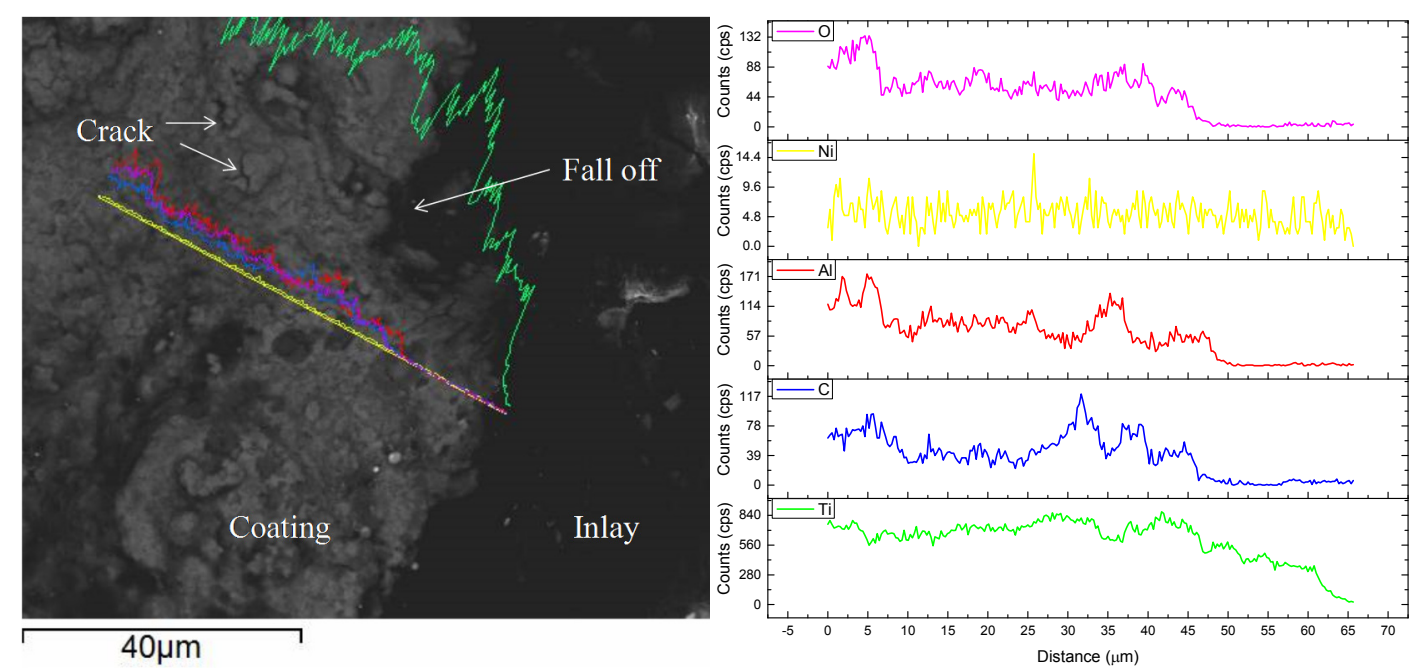

Figure 10. SEM and line scanning spectra of the cross section of the coating surface after the immersion test.

Figure 11 shows the line scanning spectra of the cross-section at the internal corrosive front after the immersion test. The non-eroded area still maintained the original organizational structure. The bright Ni phase was still visible in the erosion area, but the color of the Ni phase was lighter than that of the Ni phase in the non-eroded area. Although TiC grains could still be seen in the eroded area, the bright $\mathrm{Ni}$ phase disappeared almost completely. From the line scanning spectra, the $\mathrm{Al}$ content gradually decreased to zero from the eroded area to non-eroded area. The spectrum peaks and valleys 
of $\mathrm{Al}$ were nearly consistent with those of $\mathrm{Ni}$, which indicated that the peak positions of $\mathrm{Al}$ and $\mathrm{Ni}$ had more $\mathrm{AlNi}_{3}$ produced by reaction of $\mathrm{Al}$ with the Ni binder phase. The spectrum peaks and valleys of $\mathrm{Ti}$ were nearly consistent with those of $\mathrm{C}$ and completely different to those of $\mathrm{Al}$ and $\mathrm{Ni}$, which suggested that $\mathrm{Ti}$ and $\mathrm{C}$ peak positions were $\mathrm{TiC}$ instead of $\mathrm{AlNi}_{3} . \mathrm{TiO}_{2}$ generated before on the surface of $\mathrm{TiC}$ particles hindered the further diffusion of oxygen within $\mathrm{TiC}$ particles. At the same time, the oxygen content inside the coatings is relatively low, so TiC particles inside the coating were barely oxidized. Therefore, the corrosive mechanism that occurred at the corrosion front involves the Ni binder phase of coating being etched by aluminum to form $\mathrm{AlNi}_{3}$, while the TiC skeleton still maintains the original organizational structure.
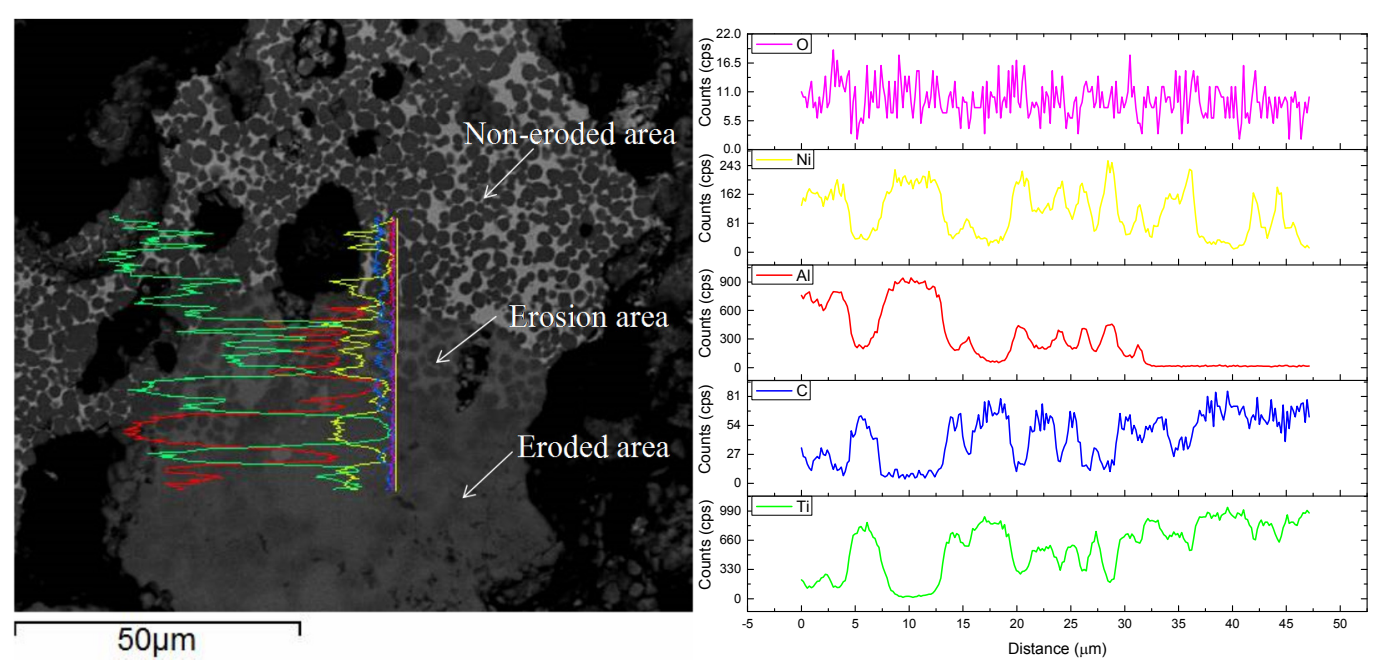

Figure 11. SEM and line scanning spectra of the cross section at the internal erosion front after the immersion test.

\subsection{Thermal Fatigue Test}

Figure 12 shows the cracks of coating surface after 600 thermal fatigue cycles. As shown in Figure 12, a severe crack could be observed on the surface of the original coating. Figure 13 shows the micrograph of the cross section of the original coating after 600 thermal fatigue cycles. From Figure 13, there was a main crack that was located from the surface to the substrate interface and was perpendicular to the interface. However, the crack did not extend to the H13 steel substrate or along the coating-substrate interface due to the high hardness of substrate. This crack was caused by the high-temperature gradients through the whole thickness and surface thermal stress on the original coating [25]. It was also noticeable that the crack passed through a large number of defects, such as micro-pores and inclusions, as can be seen from Figure 13. Stress concentration is often produced at the coating defects, especially at sharp angles, which results in the local stress exceeding the yield strength of the coating material to produce the local plastic strain. When the local plastic strain accumulates to a certain extent, the material ductility is exhausted and coating material is no longer able to absorb the deformation during thermal cycling. After this, a crack will form, which is typical for low-cycle fatigue [32]. At the same time, the thermal expansion coefficients of TiC-reinforced phase and Ni binder phase in the coating are strikingly different, which further aggravates the crack formation.

Figure 14 shows the crack propagation in the coating. As shown in Figure 14, the crack propagation mainly occurred in the $\mathrm{TiC}$ grains rather than along the grain boundaries of the TiC-reinforced phase and Ni binder phase, which is a typical feature of trans-granular fractures rather than intergranular fractures. At the same time, it also showed that the interfacial bonding strength between the in situ TiC grains and $\mathrm{Ni}$ grains was larger than that of $\mathrm{TiC}$ grains. Due to better wetting of $\mathrm{TiC}$ and $\mathrm{Ni}$ (wetting angle is 30) [33], there is a thin diffusion layer at the interface between TiC and Ni. This resulted in 
strong interfacial bonding strength between $\mathrm{TiC}$ and Ni phases. TiC ceramics are brittle and, therefore, crack propagation occurred mainly in $\mathrm{TiC}$ grains.

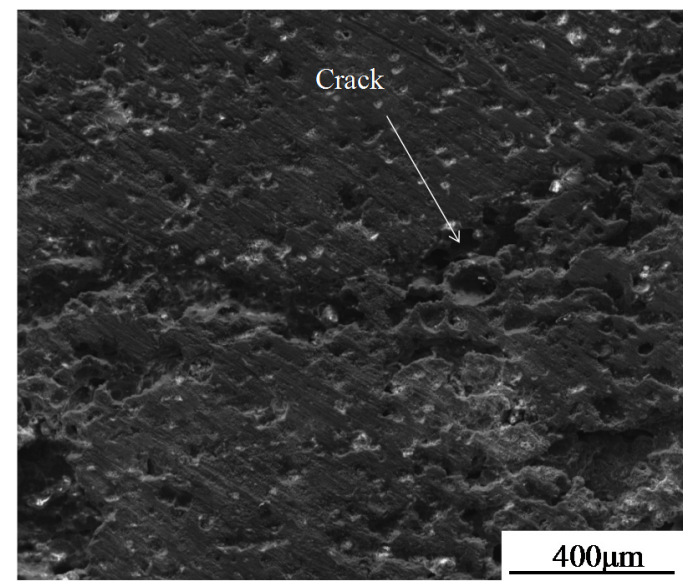

Figure 12. Thermal fatigue crack on the surface of the original coating.

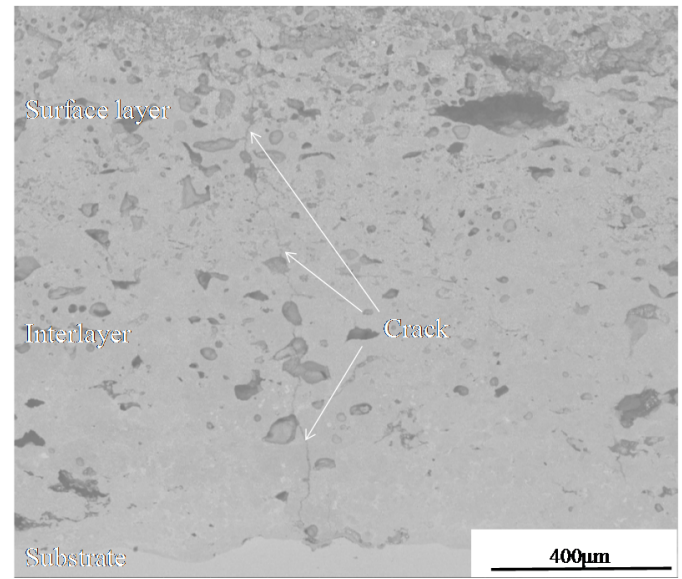

Figure 13. Micrograph of the cross-section of the original coating after 600 thermal fatigue cycles.

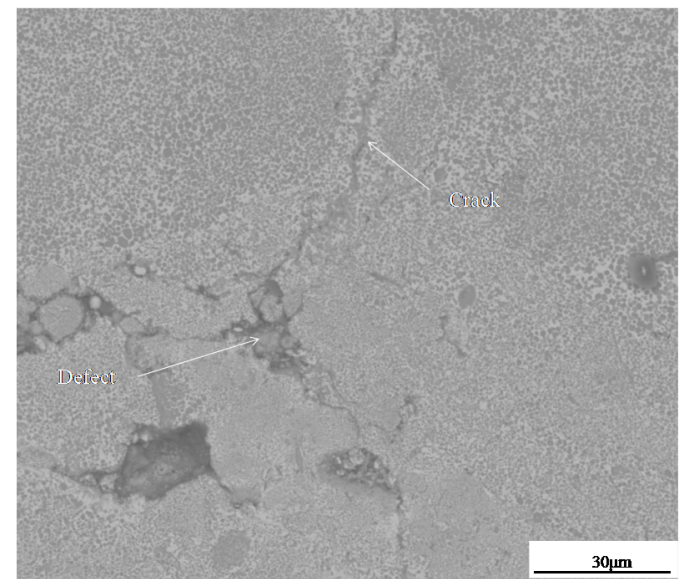

Figure 14. Crack propagation in the coating. 


\section{Conclusions}

The TiC/Ni composite coatings on $\mathrm{H} 13$ steel plate were fabricated by SHS/PHIP. The microstructure, microhardness, interfacial bonding performance, corrosion, and thermal fatigue behaviors of the original coating were investigated. The following conclusions can be drawn:

- $\quad$ The in situ coating consisted of the TiC-reinforced phase and Ni binder phase. Spheroidal TiC particles were enveloped by a nearly-continuous Ni binder phase.

- Coating shows good metallurgical bonding in the interface.

- The corrosive mechanism of the coating surface in molten aluminum alloy involves the Ni binder phase being etched by aluminum to form $\mathrm{AlNi}_{3}$ and the oxidization of the TiC-reinforced phase. The corrosive mechanism that occurred at the corrosive front involves the Ni binder phase of the coating being etched by aluminum to form $\mathrm{AlNi}_{3}$, while the $\mathrm{TiC}$ skeleton still maintains the original organizational structure.

- Hot fatigue cracks began at the defective tips of coating and propagated in the TiC-reinforced phase. The crack is a trans-granular fracture, which is the result of brittle rupture.

Acknowledgments: This work was financially supported by the National Natural Science Foundation of China (No. 51375353) and Open Fund of the State Key Laboratory of Refractories and Metallurgy of WUST (No. 2014QN03).

Author Contributions: Chenggang Pan and Chuanxiang Zhao conceived and designed the experiments; Chuanxiang Zhao and Dudu Liu performed the experiments; Chenggang Pan and Peng He analyzed the data; and Qingming Chang and Chenggang Pan wrote and edited the manuscript.

Conflicts of Interest: The authors declare no conflict of interest.

\section{References}

1. Pirzada, D.; Baburaj, E.G.; Govindaraju, R.; Froes, F.H. Shortlisted laser surface coating of TiC on H13 die steel: Effects on corrosion and errosion behaviour. Surf. Eng. 2000, 16, 164-168. [CrossRef]

2. Wang, Y. A study of PVD coatings and die materials for extended die-casting die life. Surf. Coat. Technol. 1997, 94-95, 60-63. [CrossRef]

3. Venkatesan, K.; Shivpuri, R. Experimental and numerical investigation of the effect of process parameters on the erosive wear of die casting dies. J. Mater. Eng. Perform. 1995, 4, 166-174. [CrossRef]

4. Yu, M.; Shivpuri, R.; Rapp, R.A. Effects of molten aluminum on H13 dies and coatings. J. Mater. Eng. Perform. 1995, 4, 175-181. [CrossRef]

5. Jiang, W.; Molian, P. Nanocrystalline TiC powder alloying and glazing of $\mathrm{H} 13$ steel using a $\mathrm{CO}_{2}$ laser for improved life of die-casting dies. Surf. Coat. Technol. 2001, 135, 139-149. [CrossRef]

6. Pan, C.G.; Wang, H.C.; Wang, H.F.; Chang, Q.M.; Wang, H.J. Microstructure and thermal physical parameters of Ni60- $\mathrm{Cr}_{3} \mathrm{C}_{2}$ composite coating by laser cladding. J. Wuhan Univ. Technol. 2010, 25, 991-995. [CrossRef]

7. Khan, F.F.; Bae, G.; Kang, K.; Kumar, S.; Jeong, T.; Lee, C. Development of cermet coatings by kinetic spray technology for the application of die-soldering and erosion resistance. Surf. Coat. Technol. 2009, 204, 345-352. [CrossRef]

8. He, S.; Fan, X.A.; Chang, Q.; Xiao, L. TiC-Fe-based composite coating prepared by self-propagating high-temperature synthesis. Metall. Mater. Trans. B 2017, 48, 1748-1753. [CrossRef]

9. He, P.; Huang, S.Y.; Huang, Z.C.; Pan, C.G.; Zou, J.; Zhang, Y.; Wang, H.C.; Cheng, X.D.; Hu, J.H.; Wang, H.J. Carbide reinforced Ni-Cr-B-Si-C composite coating on 4Cr5MoSiV1 steel by comprehensive plasma melt injection method. Surf. Coat. Technol. 2015, 266, 134-145. [CrossRef]

10. Zhang, X.H.; Han, J.C.; He, X.D.; Kvanin, V.L. Combustion synthesis and thermal stress analysis of TiC-Ni functionally graded materials. J. Mater. Synth. Process. 2000, 8, 29-34. [CrossRef]

11. Xiao, G.; Fan, Q.; Gu, M.; Wang, Z.; Jin, Z. Dissolution-precipitation mechanism of self-propagating high-temperature synthesis of TiC-Ni cermet. Mater. Sci. Eng. 2004, 382, 132-140. [CrossRef]

12. Odawara, O.; Ikeuchi, J. Alumina and zirconia ceramic lined pipes produced by a centrifugal-thermit process. Trans. Jpn. Inst. Met. 1986, 27, 702-708. [CrossRef] 
13. Odawara, O. Ceramic lined pipes produced by a centrifugal-thermit process. Trans. Jpn. Inst. Met. 1985, 26, 578-586. [CrossRef]

14. Odawara, O. Long ceramic-lined pipes produced by a centrifugal-thermit process. J. Am. Ceram. Soc. 1990, 3, 629-633. [CrossRef]

15. Yang, Y.W.; Fu, Z.Y.; Yuan, R.Z. In-situ synthesis and characteristics of TiC-Fe cermet graded composite coating on a steel substrate. J. Wuhan Univ. Technol. 2003, 18, 14-17.

16. Levashov, E.A.; Mukasyan, A.S.; Rogachev, A.S.; Shtansky, D.V. Self-propagating high-temperature synthesis of advanced materials and coatings. Int. Mater. Rev. 2017, 62, 203-239. [CrossRef]

17. Yuan, X.; Liu, G.; Jin, H.; Chen, K. In situ synthesis of TiC reinforced metal matrix composite (MMC) coating by self propagating high temperature synthesis (SHS). J. Alloy. Compd. 2011, 509, L301-L303. [CrossRef]

18. Riyadi, T.W.B.; Zhang, T.; Marchant, D.; Zhu, X. Synthesis and fabrication of NiAl coatings with Ti underlayer using induction heating. Surf. Coat. Technol. 2014, 258, 154-159. [CrossRef]

19. Mohammadkhani, S.; Jajarmi, E.; Nasiri, H.; Vahdati-Khaki, J.; Haddad-Sabzevar, M. Applying FeAl coating on the low carbon steel substrate through self-propagation high temperature synthesis (SHS) process. Surf. Coat. Technol. 2016, 286, 383-387. [CrossRef]

20. Boromei, I.; Casagrande, A.; Tarterini, F.; Poli, G.; Veronesi, P.; Rosa, R. Ni-Al-Ti coatings obtained by microwave assisted SHS: Oxidation behaviour in the $750-900{ }^{\circ} \mathrm{C}$ range. Surf. Coat. Technol. 2010, 204, 1793-1799. [CrossRef]

21. Bautista, C.S.; Ferriere, A.; Rodríguez, G.P.; López-Almodovar, M.; Barba, A.; Sierra, C.; Vázquez, A.J. $\mathrm{NiAl}$ intermetallic coatings elaborated by a solar assisted SHS process. Intermetallics 2006, 14, 1270-1275. [CrossRef]

22. Chatterjee, S.; Ganesh, P.; Palai, R.; Wu, J.A.; Kaul, R.; Majumdar, J.D.; Choudhury, A.R. Effect of h-BN addition on the properties of nanostructured $\mathrm{Al}_{2} \mathrm{O}_{3}-\mathrm{TiB}_{2}-\mathrm{TiN}$ based coatings developed by combined SHS and laser surface alloying. Surf. Coat. Technol. 2010, 204, 1702-1709. [CrossRef]

23. Humenik, M.; Parikh, N.M. Cermets: I, Fundamental concepts related to micro-structure and physical properties of cermet systems. J. Am. Ceram. Soc. 1956, 39, 60-63. [CrossRef]

24. Klobčar, D.; Tušek, J. Thermal stresses in aluminum alloy die casting dies. Comp. Mater. Sci. 2008, 43, 1147-1154. [CrossRef]

25. Klobčar, D.; Tušek, J.; Taljat, B. Thermal fatigue of materials for die-casting tooling. Mat. Sci. Eng. 2008, 472, 198-207. [CrossRef]

26. Dunmead, S.D.; Readey, D.W.; Semler, C.E.; Hol, J.B. Kinetics of combustion synthesis in the Ti-C and Ti-C-Ni systems. J. Am. Ceram. Soc. 1989, 72, 2318-2324. [CrossRef]

27. Zhang, X.; He, X.; Han, J.; Qu, W.; Kvalin, V.L. Combustion synthesis and densification of large-scale TiC- $x \mathrm{Ni}$ cermets. Mater. Lett. 2002, 56, 183-187. [CrossRef]

28. Han, J.C.; Zhang, X.H.; Wood, J.V. In-situ combustion synthesis and densification of TiC- $x$ Ni cermets. Mater. Sci. Eng. 2000, 280, 328-333.

29. Wong, J.; Larson, E.M.; Holt, J.B.; Waide, P.A.; Rupp, B.; Frahm, R. Time-resolved X-ray diffraction study of solid combustion reactions. Science 1990, 249, 1406-1409. [CrossRef] [PubMed]

30. Yang, Y.F.; Wang, H.Y.; Wang, J.G.; Jiang, Q.C. Effect of C particle size on the mechanism of self-propagation high-temperature synthesis in the Ni-Ti-C system. J. Alloy. Compd. 2011, 509, 7060-7065. [CrossRef]

31. LaSalvia, J.C.; Kim, D.K.; Lipsett, R.A.; Meyers, M.A. Combustion synthesis in the Ti-C-Ni-Mo system: Part I. Micromechanisms. Metall. Mater. Trans. A 1995, 26, 3001-3009. [CrossRef]

32. Klobčar, D.; Kosec, L.; Kosec, B.; Tušek, J. Thermo fatigue cracking of die casting dies. Eng. Fail. Anal. 2012, 20, 43-53. [CrossRef]

33. Durlu, N. Titanium carbide based composites for high temperature applications. J. Eur. Ceram. Soc. 1999, 19, 2415-2419. [CrossRef]

(C) 2017 by the authors. Licensee MDPI, Basel, Switzerland. This article is an open access article distributed under the terms and conditions of the Creative Commons Attribution (CC BY) license (http:/ / creativecommons.org/licenses/by/4.0/). 